This is an author produced version of a paper published in Gynecologic Oncology. This paper has been peer-reviewed but does not include the final publisher proof-corrections or journal pagination.

Citation for the published paper:

Valentin, Lil and Ameye, Lieveke and Testa, Antonia and Lécuru, Fabrice and Bernard, Jean-Pierre and Paladini, Dario and Van Huffel, Sabine and Timmerman, Dirk.

"Ultrasound characteristics of different types of adnexal malignancies." Gynecologic Oncology, 2005, Issue: Dec 27. http://dx.doi.org/10.1016/j.ygyno.2005.11.015

Access to the published version may require journal subscription. Published with permission from: Elsevier 


\section{Ultrasound characteristics of different types of adnexal malignancies}

Lil Valentin ${ }^{1}, \mathrm{MD}, \mathrm{PhD}$, Lieveke Ameye ${ }^{2}, \mathrm{MS}$, Antonia Testa ${ }^{3}, \mathrm{MD}$, Fabrice Lécuru ${ }^{4}, \mathrm{MD}, \mathrm{PhD}$, Jean-Pierre Bernard ${ }^{5}$, MD, Dario Paladini ${ }^{6}$, MD, Sabine Van Huffel $^{2}$, PhD, Dirk Timmerman ${ }^{7}$, MD, $\mathrm{PhD}$.

${ }^{1}$ Department of Obstetrics and Gynecology, Malmö University Hospital, Lund University, Malmö, Sweden

${ }^{2}$ Department of Electrical Engineering, ESAT-SCD, Katholieke Universiteit Leuven, Leuven, Belgium

${ }^{3}$ Istituto di Clinica Ostetrica e Ginecologica, Università Cattolica del Sacro Cuore, Roma, Italy

${ }^{4}$ Service de Chirurgie Gynécologique, Hôpital Européen Georges Pompidou, Paris, France

${ }^{5}$ Service Gynecologie-Obstétrique, Centre medical des pyramides, Maurepas, France

${ }^{6}$ Department of Obstetrics and Gynecology, University "Federico II" of Naples, Naples, Italy

${ }^{7}$ Department of Obstetrics and Gynecology, University Hospitals KU Leuven, Leuven, Belgium.

\section{Correspondence to}

Professor Lil Valentin, Department of Obstetrics and Gynecology, Malmö University Hospital, SE 20502 Malmö, Sweden

Phone + 4640 332094, Fax +4640962600

e-mail: lil.valentin@med.lu.se

Running head Ultrasound characteristics of adnexal malignacies

Key words ovarian neoplasms, ultrasonography 


\begin{abstract}
Objective. To describe ultrasound characteristics of adnexal malignancies, i.e., borderline ovarian tumors, primary invasive ovarian epithelial cancer stage 1, primary invasive ovarian epithelial cancer stage $2-4$, rare types of malignancy, and metastatic tumors.
\end{abstract}

Methods. In a prospective international study involving nine European ultrasound centers, 1066 women with a pelvic mass judged to be of adnexal origin underwent transvaginal gray scale and color Doppler ultrasound examination by a skilled examiner before surgery. A standardized examination technique and predefined definitions of ultrasound characteristics were used.

Results. Of 1066 masses, 266 were malignant and are included: 55 ovarian borderline tumors, 144 primary invasive epithelial ovarian cancers (42 stage 1, 102 stage 2 - 4), 25 rare malignancies, and 42 metastatic tumors. Most (56\%) metastatic tumors and most (60\%) rare types of tumor were solid and richly vascularized at color Doppler ultrasound examination (on a scale ranging from 1 to 4 color score based on subjective evaluation was 3 or 4 in $88 \%$ and $86 \%$, respectively). Borderline ovarian tumors and stage 1 primary invasive ovarian epithelial cancers differed from stage $2-4$ primary invasive ovarian epithelial cancers: they were larger (median volume $375 \mathrm{ml}$ and $695 \mathrm{ml}$ vs. $209 \mathrm{ml} ; \mathrm{p}=0.0213$ and 0.0001), a larger proportion contained papillary projections (64\% and 67\% vs. $41 \%$; $p=0.0072$ and 0.0054 ), they were more often multilocular cysts without solid components (18\% and $14 \%$ vs. $2 \%$; P < 0.0017 and 0.0204$)$, but they were less often purely solid (5\% and 7\% vs. 38\%; $\mathrm{p}=<0.0001$ and 0.0005$)$. With increasing degree of invasiveness - from borderline epithelial ovarian tumors via stage 1 invasive epithelial ovarian tumors to stage $2-4$ invasive epithelial ovarian tumors - ascites became more common (9\% vs. $31 \%$ vs. $61 \% ; \mathrm{p}=0.0082,<0.0001$ and 0.0017 ), and among tumors with solid components $(\mathrm{n}=179)$ the proportion of tumor consisting of solid tissue increased (median $2 \%$ $10 \%-34 \% ; \mathrm{p}=0.0212,<0.0001$ and 0.0003$)$. 
Conclusion. Papillary projections are characteristic of borderline tumors and stage 1 primary invasive epithelial ovarian cancer. A small proportion of solid tissue at ultrasound examination makes a malignant mass more likely to be a borderline tumor or a stage 1 epithelial ovarian cancer than an advanced ovarian cancer, a metastasis, or a rare type of tumor. 


\section{Introduction}

To plan optimal treatment of adnexal tumors it is important to be able to correctly discriminate between benign and malignant lesions. Ultrasound examination is a relatively simple and cheap diagnostic method, and an experienced ultrasound examiner can often confidently and correctly distinguish between benign and malignant pelvic masses on the basis of subjective evaluation of gray scale and color Doppler ultrasound findings [1, 2, 3]. The reported sensitivity and specificity with regard to malignancy of subjective evaluation in the studies cited were $88 \%$ and $96 \%{ }^{1}$, and $96 \%$ and $90 \%{ }^{2}$, and the reported sensitivity and specificity with regard to endometrioma were 92\% and $97 \%$, with regard to dermoid cyst $90 \%$ and $98 \%$, and with regard to hydrosalpinx $100 \%$ and $100 \%{ }^{3}$. For optimal planning of treatment it would be clinically useful to be able to distinguish not only between benignity and malignancy or between different types of benign pathology but also between different types of malignancy, for instance between ovarian borderline tumors, early and advanced ovarian cancer, and pelvic metastases.

The aim of this study was to describe clinical characteristics and ultrasound characteristics of different types of adnexal malignancies, i.e., borderline ovarian tumors, primary invasive epithelial ovarian cancer stage 1 , primary invasive epithelial ovarian cancer stage 2 - 4, rare types of pelvic malignancy, and metastatic tumors in the pelvis.

\section{Patients and methods}

The patients included in this study are a subgroup of the 1066 patients included in the International Ovarian Tumor Analysis (IOTA ) study, i.e., those 266 patients who had a pelvic mass that was suspected both clinically and at ultrasound examination to be of adnexal origin and was then histologically proven to be malignant. A short description of the IOTA study is given below. Details are given in a previous publication [4]. 
The IOTA study is a prospective international multicenter study including nine European ultrasound centers. The ethical committee at each participating center approved the study. Recruitment was from June 1999 to June 2002. Patients presenting with at least one adnexal mass and who underwent ultrasound examination by a principal investigator at one of the centers were eligible for inclusion. Informed consent was obtained from every woman participating in the study. A history following a standardized protocol was taken from each patient. A woman was considered to be postmenopausal, if she reported a period of at least 12 months of amenorrhea after the age of 40 years, provided that medication or disease did not explain the amenorrhea. Women 50 years or older who had undergone hysterectomy were also defined as postmenopausal. Blood samples were drawn for analysis of CA 125, but the availability of this biochemical end-point was not a requirement for inclusion. CA 125 results were unavailable to the ultrasound examiner at the time of the ultrasound examination. A transvaginal gray scale and color Doppler ultrasound examination using a high-end ultrasound system equipped with a transvaginal transducer with a frequency of $4-8 \mathrm{MHz}$ was performed in all cases. Transabdominal sonography was added, if a large mass could not be seen in its entirety using a transvaginal probe. A standardized examination technique and standardized definitions of ultrasound terms were used in all centers. The standardized terms and definitions have been published [5]. A papillary projection was defined as any solid protrusion into a cyst cavity from the cyst wall with a height greater than or equal to $3 \mathrm{~mm}$ [5]. In case of more than one pelvic mass, data from the mass with the most complex ultrasound morphology were used. Exclusion criteria were: pregnant patient, inability to tolerate transvaginal sonography, surgery $>120$ days after sonographic assessment, disagreement in the classification (malignant or benign) between the original pathology report and the report of an external expert reviewer, or incomplete 
submission of data. Data were submitted via the internet to a central database using a dedicated, secure data collection system developed for the study [6].

\section{Statistical analysis}

Statistical analysis was carried out by the statistician of our team (LA) using the SAS System release 8.02. Malignancies were divided into five groups, i.e., borderline ovarian tumors, primary invasive epithelial ovarian cancer stage 1, primary invasive epithelial ovarian cancer stage 2 - 4, primary invasive malignancies of rare type all stages, and metastatic tumors. Clinical and ultrasound characteristics were compared between these groups of tumor. The statistical significance of any differences between ovarian borderline tumors, primary invasive epithelial ovary cancer stage 1 and primary invasive epithelial ovary cancer stage 2 - 4 was determined using the Kruskal-Wallis test or analysis of variance for continuous data and the Chi-squared test (Mantel-Haenszel Chi-square when appropriate) or Fisher's exact test for discrete data. To correct for multiple testing when comparing paired results between the three groups of tumor (borderline ovarian tumors, stage 1 and stage 2 - 4 ovarian epithelial cancers) Bonferroni's correction was used with $\mathrm{p}<0.0167(0.05 / 3)$ being the criterion for statistical significance. Within categorical variables with many categories (e.g., echogenicity of cyst fluid, type of tumor, color score) permutation methods were used, because in these cases Bonferroni's correction would have been too conservative. In these cases, too, a p-value of $<0.0167$ was considered statistically significant.

Multivariable logistic regression with stepwise selection of variables was used in the group of borderline tumors and stage 1 primary invasive epithelial cancers $(n=97)$ to determine which clinical variables and which ultrasound features were independently associated with invasiveness, a p-value $<0.05$ being the threshold for including a variable in the model. 
The funding bodies had no role in the design of the study, the analysis, the interpretation of results, the drafting of the report, or the decision to submit the paper for publication.

\section{Results}

There were 55 borderline ovarian tumors (50 stage 1, five stage 2), 42 epithelial ovarian cancers stage 1 (20 grade 1 , nine grade 2, nine grade 3, and four with unknown grade), 102 epithelial ovarian cancers stage 2 - 4 (eight grade 1, 24 grade 2, 65 grade 3, and five of unknown grade), 25 primary invasive malignancies of rare type, and 42 metastatic tumors. The histopathological diagnoses are presented in Table 1.

Clinical information including CA125 values for the five groups of tumor are shown in Table 2. Patients with borderline tumors and rare types of malignancy were younger than those with invasive epithelial ovarian cancer or metastases (mean 50 years \pm 16.3 , SD, vs. $60 \pm 12.8$; $\mathrm{p}=$ $<0.0001)$. Of patients with ovarian epithelial malignancies those with borderline tumors were the youngest. Patients with primary invasive epithelial ovarian cancer stage $2-4$ had the highest CA 125 values.

Ultrasound findings are shown in Table 3. The metastatic tumors tended to be small, solid, and well vascularized. The rare malignancies tended to be large, solid, and well vascularized. Fiftyeight per cent (39/67) of the rare and metastatic tumors were purely solid vs. 23\% (45/199) of borderline tumors and primary invasive ovarian epithelial cancers ( $\mathrm{p}=<0.0001)$. Fluid in the pouch of Douglas or ascites were common features both of metastatic tumors and rare types of tumor. Borderline ovarian tumors and stage 1 primary invasive ovarian epithelial cancers had several ultrasound features in common that differed from those of stage $2-4$ primary invasive ovarian epithelial cancers: they were larger $(p=0.0213 ; p=0.0001)$, a much greater proportion of them contained papillary projections ( $\mathrm{p}=0.0072$; $\mathrm{p}=0.0054)$, they were more often multilocular cysts $(\mathrm{p}=0.0017 ; \mathrm{p}=0.0204)$, but they were less often purely solid tumors ( $\mathrm{p}$ 
$<0.0001 ; \mathrm{p}=0.0005)$; their cyst fluid was more often characterized as having low level echogenicity $(p=0.0084: p=0.0022)$ or ground glass appearance $(p=0.0008 ; p=0.0018)$. With increasing degree of invasiveness (from borderline epithelial ovarian tumors via stage 1 invasive epithelial ovarian tumors to stage 2 - 4 epithelial ovarian tumors) ascites became increasingly more common ( $9 \%$ vs. $31 \%$ vs. $61 \%$ of cases; $\mathrm{p}<0.0001$ ), and among tumors with solid components $(n=179)$ the proportion of tumor consisting of solid tissue increased (median $2 \%$ $10 \%-34 \%$; $<0.0001)$. However, the proportion of tumor consisting of solid tissue was highest in rare tumors and in metastases (median proportion 100\% in both types of tumor; KruskallWallis test applied to all five groups of tumor yielded a p-value $<0.0001$ when comparing the proportion of tumor being solid).

Within the group of primary invasive epithelial cancers stage 1 , grade 1 cancers more often contained papillary projections than grade $2-3$ cancers ( $85 \%$ vs. 50\%, i.e., 17/20 vs. 9/18; p = .0354), if solid components were present the volume of the largest solid component was smaller (median $14 \mathrm{ml}$ vs. $176 \mathrm{ml}$; $\mathrm{p}=0.0020$ ) and the proportion of the tumor consisting of solid tissue was smaller (median $4 \%$ vs. 26\%; $p=0.0026$ ) in grade 1 cancers than in grade $2-3$ cancers, and fewer stage 1 grade 1 cancers had color score 3 - 4 (60\% vs. 100\%, i.e., 12/20 vs.18/18; p = 0.0035). We found no other statistically significant differences in clinical variables or ultrasound variables between grade 1 and grade 2 - 3 tumors among the primary epithelial ovarian cancers stage 1.

Multivariable logistic regression in the 55 borderline tumors and the 42 stage 1 ovarian epithelial cancers showed ascites (odds ratio, OR 5 .991, 95\% CI confidence interval 1.743 20.586), nulliparity (OR 3.726, 95\% CI 1.254 - 11.074), and age (OR 1.056, 95\% CI 1.019 1.095) to be the only independent predictors of invasiveness. CA 125 did not enter the model. 


\section{Discussion}

Most experienced ultrasound examiners using high-end ultrasound systems can reliably discriminate between benign and malignant extrauterine pelvic masses on the basis of gray scale and color Doppler ultrasound findings [1, 2, 3]. This is because benign and malignant tumors have different ultrasound characteristics. This study has shown that different types of malignant extrauterine pelvic tumor, too, manifest different ultrasound features. Metastases are often small, solid, well vascularized masses accompanied by fluid in the pelvis, and many rare types of tumor are large, solid, well vascularized tumors accompanied by fluid in the pelvis. Of the epithelial adnexal malignancies, borderline ovarian tumors and stage 1 invasive ovarian cancers tend to be larger than stage 2 - 4 invasive ovarian cancers. A very characteristic feature of both borderline epithelial ovarian tumors and stage 1 epithelial ovarian tumors (particularly if grade 1 ) is the presence of papillary projections. The more advanced an epithelial ovarian malignancy is the greater is the proportion of solid tissue within the tumor, and the more vascularized does the tumor seem to be at color Doppler ultrasound examination. On the other hand, because most malignant adnexal tumors are well vascularised (see table 3) the degree of vascularisation (color score) may not be very helpful when one tries to discriminate between different types of malignancy. Nor do PI, RI and blood flow velocities seem to be very helpful, because of $\underline{\text { considerable overlap in results between different types of malignancy. CA } 125 \text { levels also would }}$ not be very helpful for distinguishing between different types of adnexal malignancy because of overlap in results. Possibly one could say that extremely high Ca 125 values would be suggestive of advanced invasive primary epithelial cancer.

In a group of tumor comprising only borderline tumors and stage 1 ovarian epithelial cancer.multivariate logistic regression showed that the risk of invasive malignancy increased with the woman's age, nulliparity and the presence of ascites, but that no other ultrasound variables 
than ascites predicted invasiveness, and that $\mathrm{Ca} 125$ was not helpful for discrimination between borderline tumor and stage 1 epithelial ovarian cancer.

Our intention is not that our results should be extrapolated to general community practice. We describe that different types of pelvic malignancy have different clinical and ultrasound characteristics. This information may help skilled ultrasound examiners to suggest a correct diagnosis.

The similarity between the ultrasound morphology of borderline tumors and stage 1 invasive epithelial tumors and the dissimilarity between the ultrasound morphology of these two types of tumor and that of stage $2-4$ ovarian epithelial tumors agrees well with the assumption that well differentiated epithelial ovarian cancers in stage I may originate from borderline tumors. A dualistic model describing ovarian carcinogenesis has been proposed by Shih and Kurman [7]. They suggest that there are two types of surface epithelial tumors - type I tumors and type II tumors - corresponding to two main pathways of tumorigenesis. Type I tumors are low grade carcinomas that develop in a stepwise manner from well-recognized precursors, i.e., borderline tumors. They are slow-growing as evidenced by them being large and often confined to the ovary at diagnosis [7]. In contrast, type II tumors are high-grade at presentation and are rarely associated with morphologically recognizable precursor lesions. They are suggested to develop de novo from the surface epithelium of the ovary, evolve rapidly, metastasize early in their course, and to be highly aggressive [7]. There are also several distinct molecular features that distinguish type I and type II tumors [7]. The two pathways suggested by Shih and Kurman were described for serous tumors and then extrapolated to other types of tumor, i.e., mucinous carcinoma, endometrioid carcinoma, malignant Brenner tumor, and clear cell carcinoma. The dualistic model proposed by Shih and Kurman [7] is indirectly supported not only by our 
findings but also by those of a Japanese study [8]: in 54\% (19/35) of patients with ovarian carcinomas a cyst was detected at ultrasound examination 2 -12 months before surgery, all these cancers being well differentiated stage 1 cancers; in the remaining $46 \%(16 / 35)$ of ovarian carcinomas, ultrasound examinations performed 2 - 12 months before surgery had been normal, and $89 \%(8 / 9)$ of the serous tumors in this group were stage 3, grade 2 or 3.

To sum up, the possibility to discriminate preoperatively between ovarian borderline tumors, early and advanced ovarian cancer, and pelvic metastases may improve the possibility to provide optimal management. We have shown that different types of extrauterine pelvic malignancy manifest different characteristics at transvaginal ultrasound examination. The use of these ultrasound characteristics to predict the type of malignancy needs to be tested prospectively.

\section{Acknowledgement}

This study was supported by the Swedish Medical Research Council (grants nos. K2001-72X11605-06A and K2002-72X-11605-07B), two governmental grants (Landstingsfinansierad regional forskning, Region Skåne, and ALF-medel), Funds administered by Malmö University Hospital, by the Research Council of the Katholieke Universiteit Leuven, Belgium (GOAMEFISTO666, GOA-AMBioRICS), the FlemishGovernment (FWO: projects G.0407.02 / G.0269.02 /G.0360.05, research communities ICCoS \& ANMMM), the Belgian Federal Government (DWTC: IUAP IV-02(1996-2001)and IUAP V-22 (2002-2006)), and the EU(PDTCOIL: contract NNE5/2001/887; BIOPATTERN:contract FP6-2002-IST 508803; eTUMOUR: contract FP6-2002-LIFESCIHEALTH 503094).

\section{References}

1. Valentin L: Prospective cross-validation of Doppler ultrasound examination and gray-scale 
ultrasound imaging for discrimination of benign and malignant pelvic masses Ultrasound Obstet Gynecol 1999: 14 ; 273 - 283.

2. Timmerman D, Schwarzler P, Collins WP, et al: Subjective assessment of adnexal masses with the use of ultrasonography: an analysis of interobserver variability and experience. Ultrasound Obstet Gynecol 1999: 13; 11 - 16.

3. Valentin L. Pattern recognition of pelvic masses by gray-scale ultrasound imaging: the contribution of Doppler ultrasound. Ultrasound Obstet Gynecol 1999: 15; 338 - 347.

4. Dirk Timmerman, Antonia C. Testa, Tom Bourne, et al: A logistic regression model to distinguish between the benign and malignant adnexal mass before surgery: a multicenter study by the International Ovarian Tumor Analysis (IOTA) Group. J Clin Oncol 2005, In press.

5. Timmerman D, Valentin L, Bourne TH, et al: Terms, definitions and measurements to describe the sonographic features of adnexal tumors: a consensus opinion from the International Ovarian Tumor Analysis (IOTA) group. Ultrasound Obstet Gynecol 2000: 16; 500 - 505.

6. Aerts S, Antal P, Timmerman D, et al: Web based data collection for ovarian cancer: a case study. In: P Kokol (Hrsg): Proceedings of the $15^{\text {th }}$ IEEE Symposium on Computer Based Medical Systems (CBMS), 4 - 7 June 2002, Maribor, Slovenia. Los Alamitos, Calif: IEEE Computer Society 2002, pp. $213-218$

7. Shih Ie-Ming, Kurman RJ: Ovarian tumorigenesis. A proposed model based on morphological and molecular genetic analysis. Review. Am J Pathol 2004: 164; 1511 - 1518.

8. Horiuchi A, Itoh K, Shimizu M, et al: Toward understanding the natural history of ovarian carcinoma development: a clinicopathological approach. Gynecol Oncol 2003: 88; 309 - 317. 


\section{Précis}

The ultrasound morphology of malignant adnexal tumors is described. Papillary projections are characteristic of borderline tumors and stage 1 primary invasive epithelial ovarian cancer. 
Borderline ovarian tumor $(\mathrm{n}=55)$

Sero-(papillary) cystadeno(fibr)oma

Mucinous cystadeno(fibr)oma

$35 \quad(64 \%)$

Other

$13(24 \%)$

Not specified

Primary invasive epithelial ovarian cancer stage $1(n=42)$

Serous (papillary) adenocarcinoma

Edometroid adenocarcinoma

Mucinous adenocarcinoma

Clear cell carcinoma

Other

Primary invasive epithelial ovarian cancer stage $2-4(n=102)$

Serous (papillary) adenocarcinoma

Edometroid adenocarcinoma

Adenocarcinoma, unspecified

Mucinous adenocarcinoma

Clear cell adenocarcinoma

Other

Metastatic tumor $(n=42)$ from

Endometrium/uterus

Colon-rectum

Breast

Pancreas

Recurrence of ovary cancer

Other

Not specified /unknown

Rare malignancy $(\mathrm{n}=25)$

Carcinosarcoma

4

Granulosa cell tumor

3

Brenner tumor

2

Immature teratoma

2

Leydig cell tumor

2

Complex germinal tumor

Dysgerminoma and yolk sac tumor

Endodermal sinus tumor

Gynandroblastoma

Hindgut carcinoid of uncertain origin

cont. 
Number $(\% *)$

Leiomyosarcoma

Lymphoma

1

Mixed mullerian tumor $\quad 1$

Pure choriocarcinoma 1

Sex-cord stromal ovarian tumor 1

Small bowel gastrointestinal stroma cell tumor $\quad 1$

Small cell cancer of pulmunary type 1

* the percentages shown have been calculated for each group of tumor 
Table 2 Clinical information

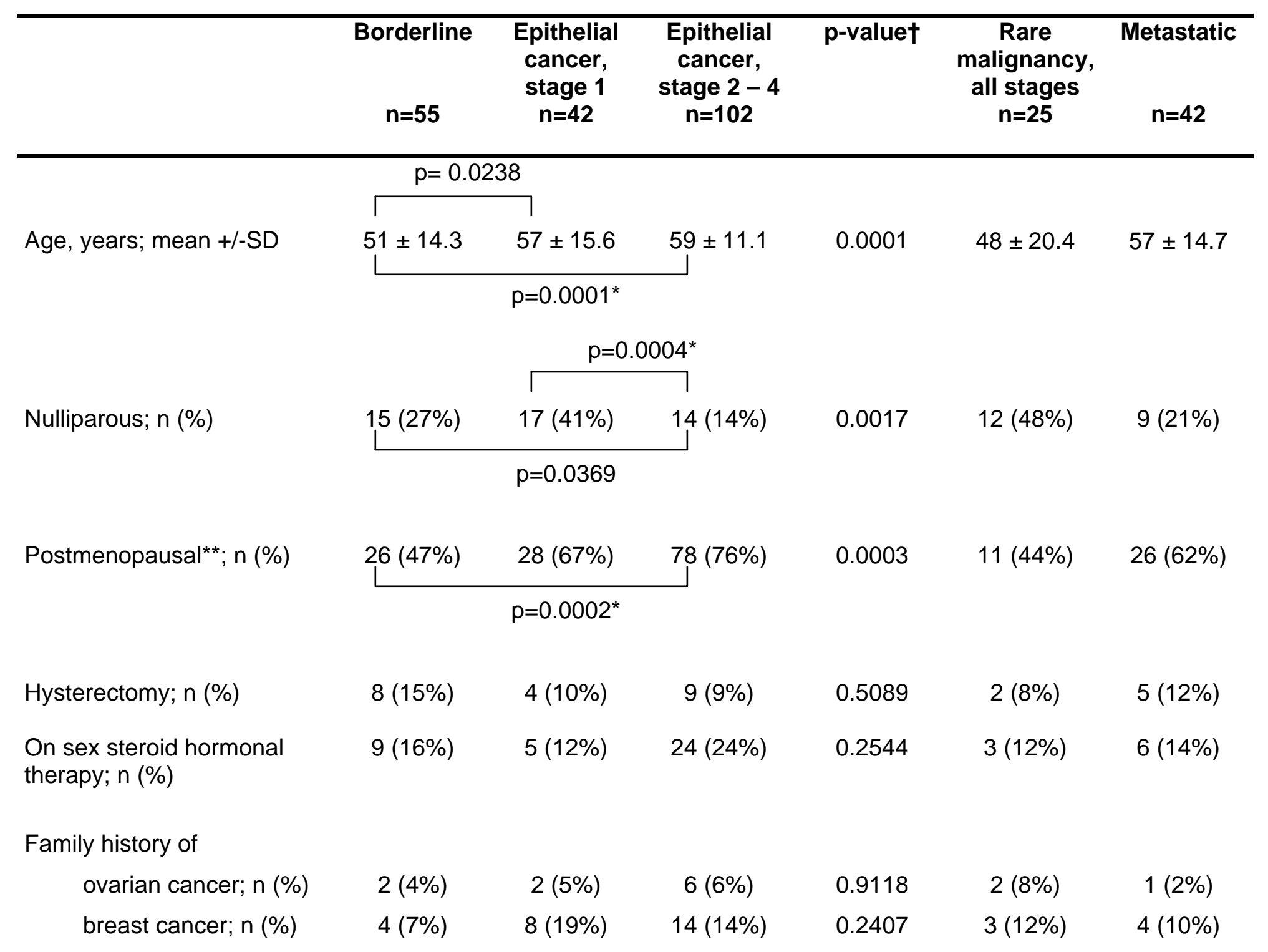


Table 2 cont.

\begin{tabular}{|c|c|c|c|c|c|c|}
\hline & $\begin{array}{c}\text { Borderline } \\
n=55\end{array}$ & $\begin{array}{c}\text { Epithelial } \\
\text { cancer, } \\
\text { stage } 1 \\
n=42\end{array}$ & $\begin{array}{c}\text { Epithelial } \\
\text { cancer, } \\
\text { stage } 2-4 \\
\text { n=102 }\end{array}$ & p-value $\dagger$ & $\begin{array}{c}\text { Rare } \\
\text { malignancy, } \\
\text { all stages } \\
n=25\end{array}$ & $\begin{array}{c}\text { Metastatic } \\
n=42\end{array}$ \\
\hline \multicolumn{7}{|l|}{ Personal history of } \\
\hline ovarian cancer; n (\%) & $2(4 \%)$ & 0 & $1(1 \%)$ & 0.2989 & 0 & $5(12 \%)$ \\
\hline breast cancer; n (\%) & 0 & $2(5 \%)$ & $8(8 \%)$ & 0.0651 & $1(4 \%)$ & $4(10 \%)$ \\
\hline \multirow{4}{*}{$\begin{array}{l}\text { Ca } 125, \mathrm{U} / \mathrm{mL} ; \text { median } \\
\text { (range) }\end{array}$} & $p=0.0307$ & $p=0.0001^{*}$ & & & & \\
\hline & 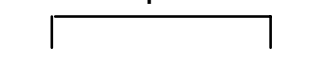 & & 7 & & & \\
\hline & $25(4-2779)$ & $76(8-5620)$ & $532(14-31610)$ & $<0.0001$ & $100(10-1189)$ & $76(5-2980)$ \\
\hline & & $p=0.0001^{*}$ & & & & \\
\hline
\end{tabular}

For pair-wise comparisons within the group of borderline tumors and primary invasive epithelial ovarian cancer only p-values $<0.05$ are shown $\dagger P$-value referring to significance testing between the following three groups: borderline, ovarian epithelial cancer stage 1 , and

ovarian epithelial cancer stage 2 - 4 using Kruskall-Wallis test, analysis of variance, the chi-squared test (Mantel-Haenszel chi-squared where appropriate), or Fisher's exact test

* Significant after correction for multiple testing, i.e., $p<0.0167$ 
Table 3 Ultrasound characteristics

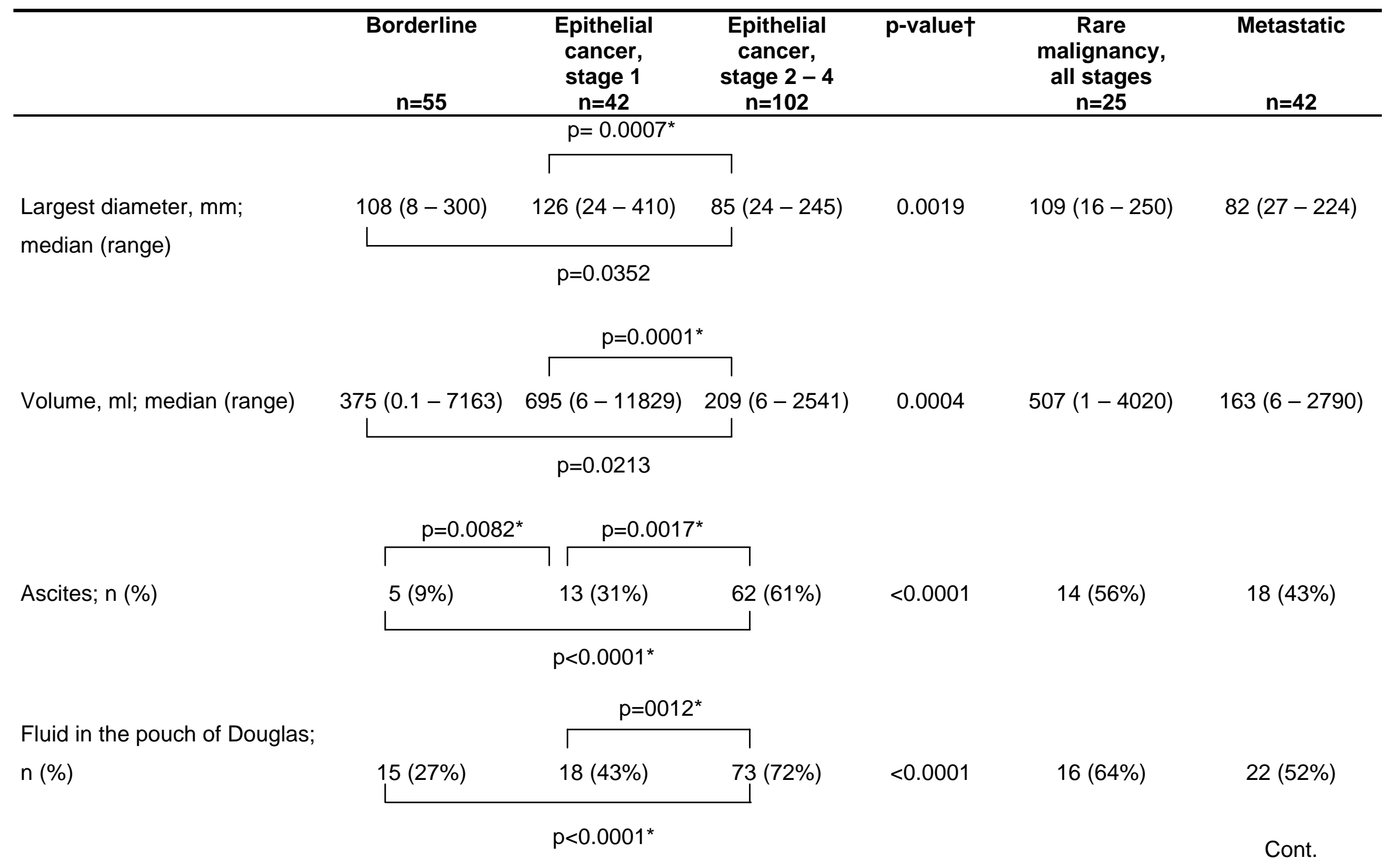


Table 3 cont.

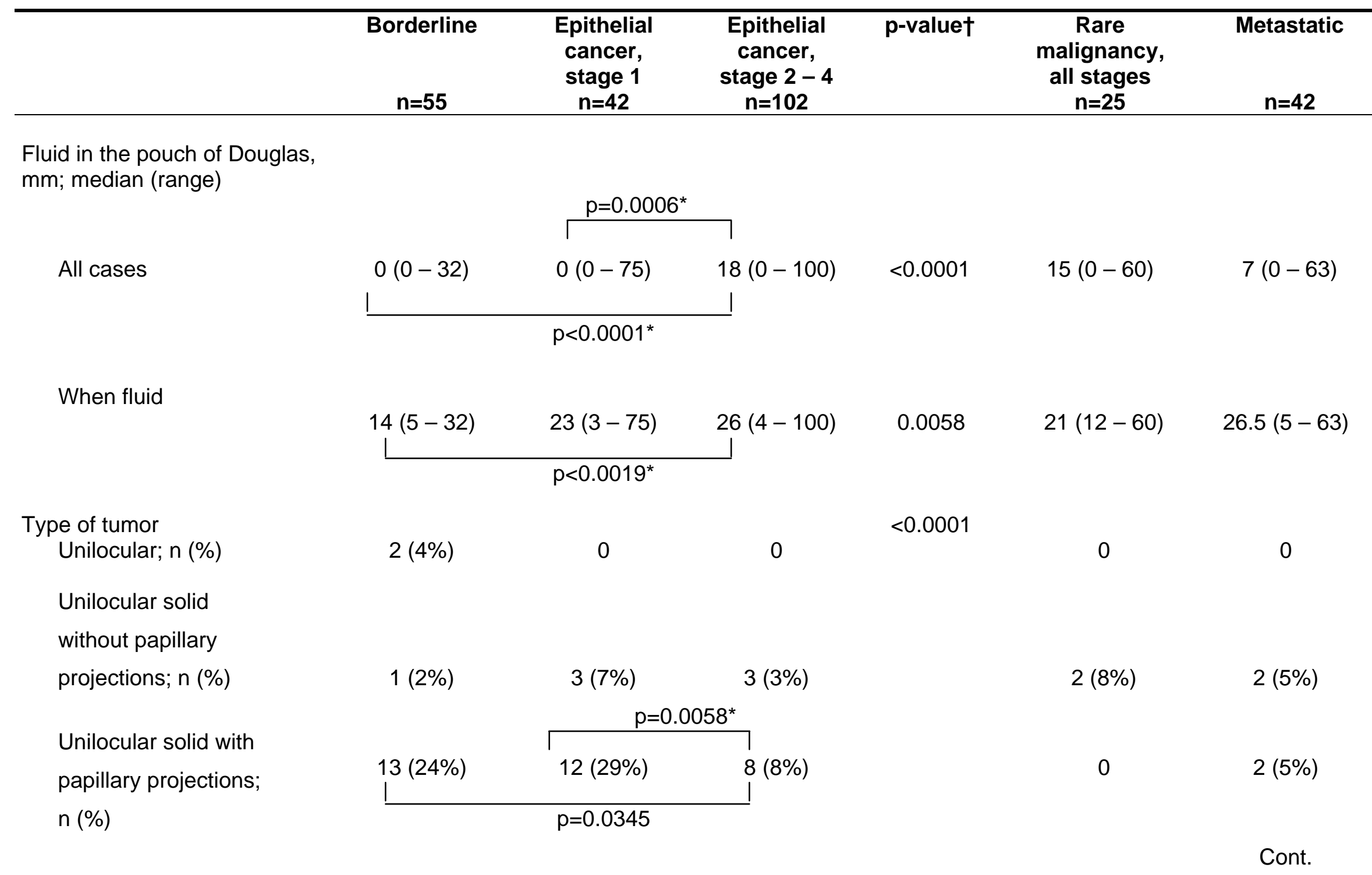


Table 3 cont.

\begin{tabular}{|c|c|c|c|c|c|c|}
\hline & $\begin{array}{c}\text { Borderline } \\
n=55\end{array}$ & $\begin{array}{c}\text { Epithelial } \\
\text { cancer, } \\
\text { stage } 1 \\
n=42\end{array}$ & $\begin{array}{c}\text { Epithelial } \\
\text { cancer, } \\
\text { stage } 2-4 \\
\mathrm{n}=102\end{array}$ & p-value $\dagger$ & $\begin{array}{c}\text { Rare } m \\
\text { alignancy, } \\
\text { all stages } \\
n=25\end{array}$ & $\begin{array}{c}\text { Metastatic } \\
n=42\end{array}$ \\
\hline \multicolumn{7}{|c|}{$\mathrm{p}=0.0204$} \\
\hline & & & 7 & & & \\
\hline \multirow[t]{2}{*}{ Multilocular; n (\%) } & $10(18 \%)$ & $6(14 \%)$ & $2(2 \%)$ & & $1(4 \%)$ & $1(2 \%)$ \\
\hline & & $p<0.0017^{\star}$ & & & & \\
\hline Multilocular solid; n (\%) & $26(47 \%)$ & $18(43 \%)$ & $50(49 \%)$ & & $8(32 \%)$ & $14(33 \%)$ \\
\hline & & & & & & \\
\hline & & $\Gamma$ & 7 & & & \\
\hline \multirow[t]{2}{*}{ Solid; n (\%) } & 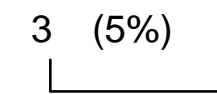 & $3(7 \%)$ & $\begin{array}{l}39 \text { (38\%) } \\
\quad\end{array}$ & & $14(56 \%)$ & $25(60 \%)$ \\
\hline & \multicolumn{3}{|c|}{$p<0.0001^{*}$} & & & Cont. \\
\hline
\end{tabular}


Table 3 cont.

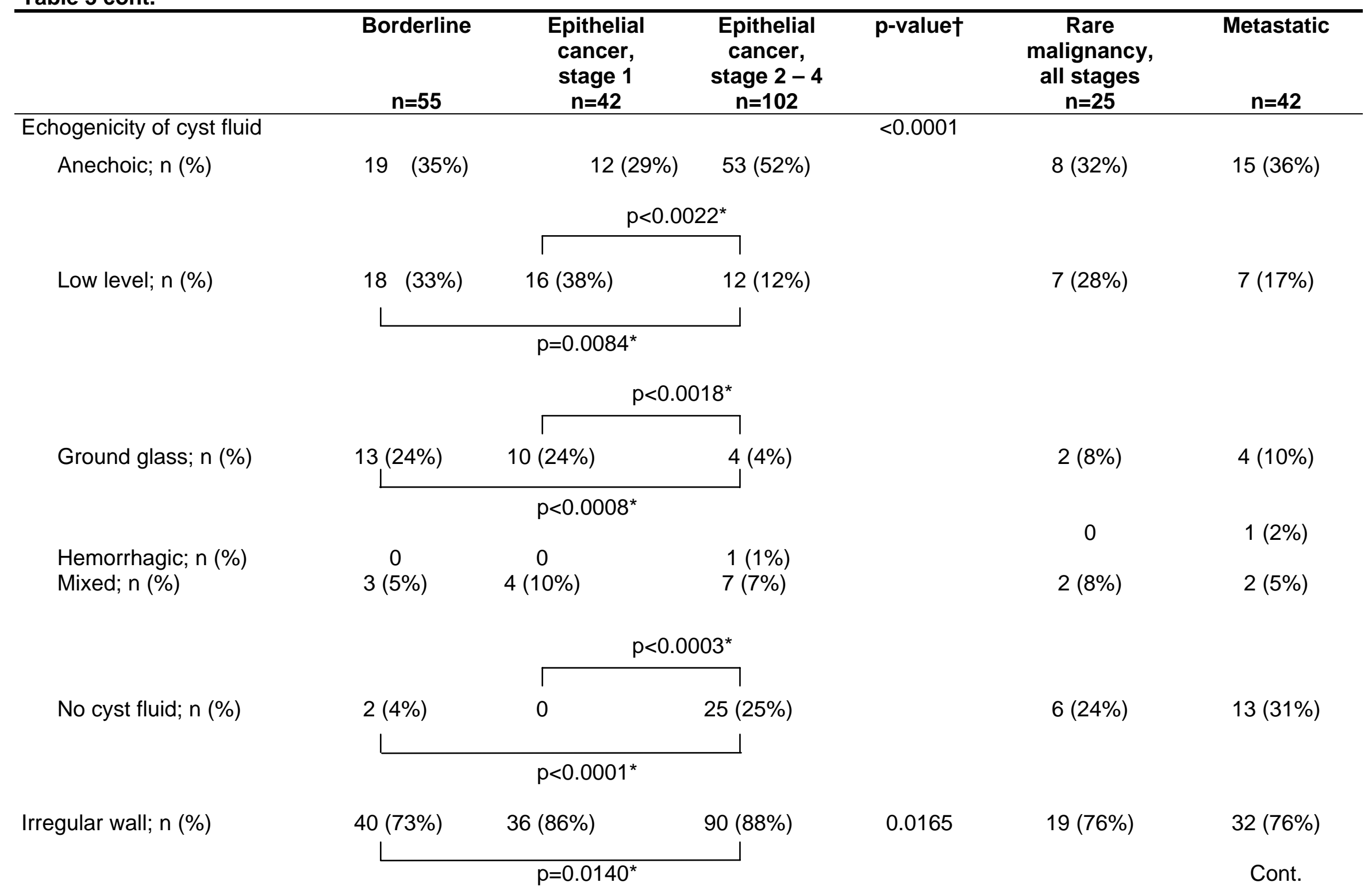


Table 3 cont.

\begin{tabular}{|c|c|c|c|c|c|c|}
\hline & $\begin{array}{c}\text { Borderline } \\
n=55\end{array}$ & $\begin{array}{c}\text { Epithelial } \\
\text { cancer, } \\
\text { stage } 1 \\
\mathrm{n}=42 \\
\end{array}$ & $\begin{array}{c}\text { Epithelial } \\
\text { cancer, } \\
\text { stage } 2-4 \\
\mathrm{n}=102 \\
\end{array}$ & p-value $\dagger$ & $\begin{array}{c}\text { Rare } \\
\text { malignancy, } \\
\text { all stages } \\
n=25\end{array}$ & $\begin{array}{c}\text { Metastatic } \\
n=42 \\
\end{array}$ \\
\hline & & $\mathrm{p}=0.0072^{*}$ & & & & \\
\hline Papillary projection present; $\mathrm{n}$ & $\Gamma$ & & & & & \\
\hline (\%) & $35(64 \%)$ & $28(67 \%)$ & $\begin{array}{l}42 \text { (41\%) } \\
+\end{array}$ & 0.0034 & $7(28 \%)$ & $9(21 \%)$ \\
\hline $\begin{array}{l}\text { Number of papillary } \\
\text { projections }^{\star *} ; \text { median }\end{array}$ & & $p=0$ & $54^{*}$ & & & \\
\hline (range) & $>3(1->3)$ & $>3(1->3)$ & $>3(1->3)$ & 0.9420 & $>3(1->3)$ & $>3(1->3)$ \\
\hline Papilla irregular**; n (\%) & $29(83 \%)$ & $22(79 \%)$ & $34(81 \%)$ & 0.9506 & $7(100 \%)$ & $8(89 \%)$ \\
\hline $\begin{array}{l}\text { Volume of largest } \\
\text { papilla** }^{\star *} \text { ml; median } \\
\text { (range) }\end{array}$ & $2(0.008-226)$ & $4(0.02-123)$ & $2(0.01-90)$ & 0.2163 & $1(0.02-90)$ & $2(0.2-12)$ \\
\hline Shadowing; n (\%) & $1(2 \%)$ & 0 & $1(1 \%)$ & 1.0 & 0 & $2(5 \%)$ \\
\hline \multicolumn{7}{|l|}{$\begin{array}{l}\text { Thickness of septum if } \\
\text { present, mm; }\end{array}$} \\
\hline median (range) & $3.9(1.4-15)$ & $4.0(1-20)$ & $5.0(1-20)$ & 0.4856 & $8.0(2.6-15)$ & $4.4(1.4-12)$ \\
\hline
\end{tabular}


Table 3 cont.

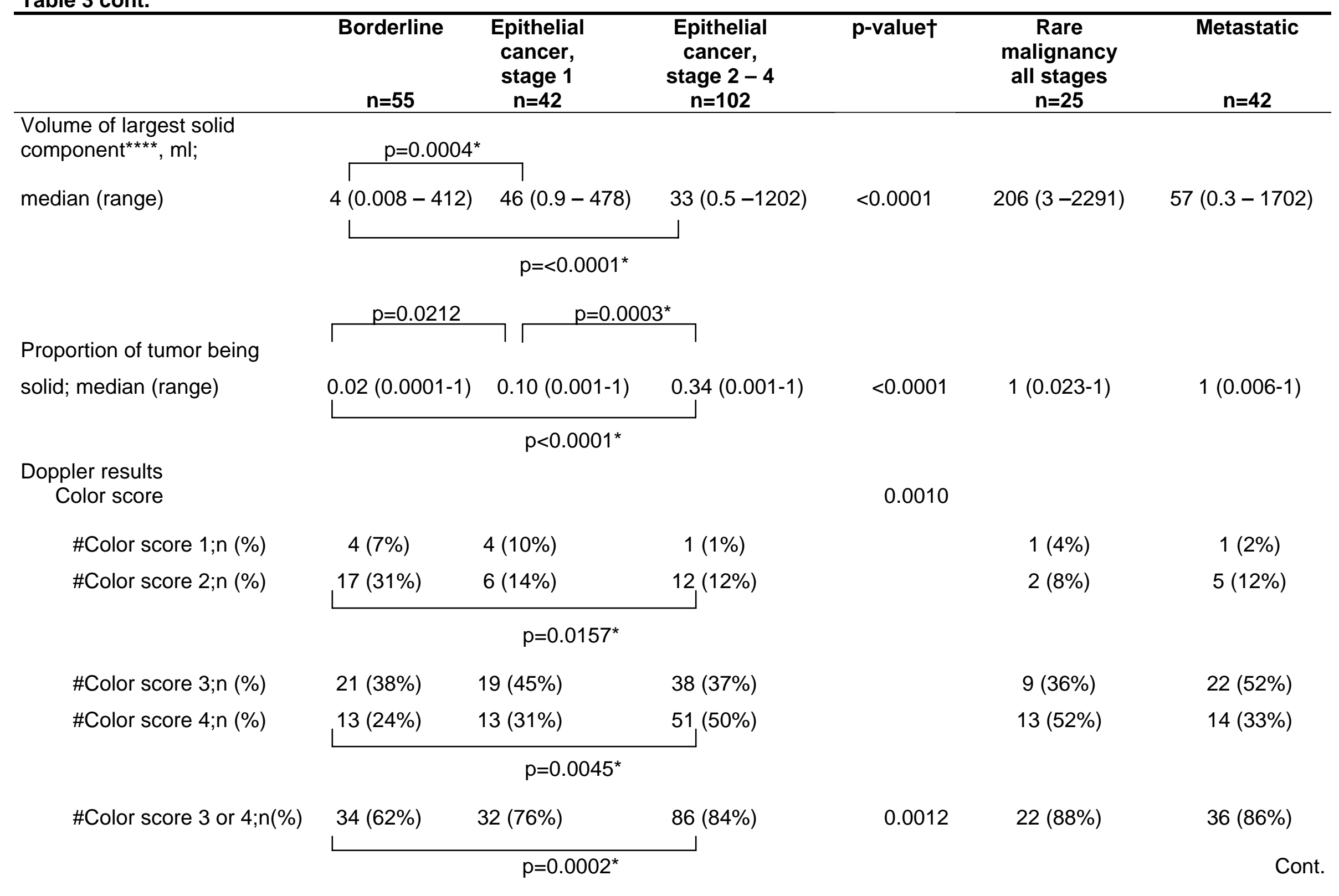




\begin{tabular}{|c|c|c|c|c|c|c|}
\hline & $\begin{array}{c}\text { Borderline } \\
n=55\end{array}$ & $\begin{array}{c}\text { Epithelial } \\
\text { cancer, } \\
\text { stage } 1 \\
\mathrm{n}=42 \\
\end{array}$ & $\begin{array}{c}\text { Epithelial } \\
\text { cancer } \\
\text { stage } 2-4 \\
n=102 \\
\end{array}$ & p-value $\dagger$ & $\begin{array}{c}\text { Rare } \\
\text { malignancy } \\
\text { all stages } \\
n=25\end{array}$ & $\begin{array}{c}\text { Metastatic } \\
n=42 \\
\end{array}$ \\
\hline \multicolumn{7}{|l|}{ Only venous flow } \\
\hline recorded; n (\%) & $3(5 \%)$ & $2(5 \%)$ & $3(3 \%)$ & 0.6360 & $1(4 \%)$ & 0 \\
\hline $\begin{array}{l}\text { Arterial flow recorded; } \\
\mathrm{n}(\%) \\
\text { Flow in papillary }\end{array}$ & $48(87 \%)$ & $36(86 \%)$ & $98(96 \%)$ & 0.0552 & $23(92 \%)$ & $41(98 \%)$ \\
\hline projection**; n (\%) & $25(71 \%)$ & $25(89 \%)$ & 37 (88\%) & 0.0887 & $7(100 \%)$ & $8(89 \%)$ \\
\hline PI; median (range) & $0.74(0.35-2.26)$ & $0.63(0.29-1.90)$ & $0.82(0.25-2.25)$ & 0.0450 & $0.64(0.33-1.44)$ & $0.76(0.36-2.05)$ \\
\hline \multicolumn{7}{|c|}{$p=0.0202$} \\
\hline $\mathrm{RI}$; median (range) & $0.48(0.30-0.87)$ & $0.44(0.26-0.78)$ & $0.55(0.17-1)$ & 0.0172 & $0.44(0.27-0.73)$ & $0.53(0.20-0.85)$ \\
\hline \multicolumn{7}{|c|}{$p=0.0078^{*}$} \\
\hline $\begin{array}{l}\text { PSV, cm/s; median } \\
\text { (range) }\end{array}$ & $19.8(5-72)$ & $25.5(3.9-86.0)$ & $25.3(4.8-120)$ & 0.1510 & $30.4(9.5-202)$ & $23.3(6.2-85.5)$ \\
\hline $\begin{array}{l}\text { TAMXV, cm/s; median } \\
\text { (range) }\end{array}$ & $13.8(3-51.6)$ & $17.7(3.1-87.0)$ & $17.4(3.1-87.0)$ & 0.1209 & $21.0(7.6-137)$ & $17.1(5.0-55.9)$ \\
\hline
\end{tabular}

For comparisons within the group of borderline tumors and primary invasive epithelial ovarian cancer only p-values $<0.05$ are shown

† P-value referring to significance testing between the following three groups: borderline, ovarian epithelial cancer stage 1, and ovarian epithelial cancer stage 2 -- 4

* Significant after correction for multiple testing, ${ }^{* \star}$ Calculated only for masses with papillary projections, ${ }^{\star \star *}$ Calculated only for masses with solid components;

papillary projections were classified as solid component \# Color score $1=$ no color detected in the mass at color Doppler ultrasound examination; Color score $2=$ minimal color detected in the mass at color Doppler ultrasound examination; Color score $3=$ moderate amount of color detected in the mass at color Doppler ultrasound examination; Color score $4=$ abundant color detected in the mass at color Doppler ultrasound examination; see reference 5

$\mathrm{PI}$, pulsatility index; RI, resistance index; PSV, peak systolic velocity; TAMXV, time averaged maximum velocity 